\title{
QUANTIFYING BEACH AND DUNE RESILIENCE USING THE COASTAL RESILIENCE INDEX
}

\author{
Zhifei Dong ${ }^{1}$, Nicole Elko ${ }^{2}$, Quin Robertson ${ }^{1}$ and Julie Rosati ${ }^{3}$
}

\begin{abstract}
US Army Corps of Engineers Coastal Storm Risk Management (CSRM) projects have reduced coastal vulnerability and helped communities anticipate and mitigate toward improved resilience. This study proposes the Coastal Resilience Index (CRI) to quantify storm damage reduction benefits due to beach restoration projects in the context of resilience. The CRI considers metrics of the beach and dune system and disturbance factors such as storm surge and waves, using five non-dimensional factors: Protective Elevation (PE), Volume Density (VD), Protective Width (PW), Crest Freeboard (CF) and wave run-up (WR). The CRI is the summation of these five non-dimensional factors. This study developed a geographic information systems (GIS) based tool to automatically extract morphologic features from historic profiles and profiles extracted from LiDAR data to quantify beach resilience over time.
\end{abstract}

Keywords: coastal resiliency; beach restoration; coastal vulnerability; storm damage reduction

\section{INTRODUCTION}

In 2013, the U.S. Army Corps of Engineers' Coastal Engineering Research Board (CERB) defined the resilience cycle with four concepts: prepare, resist, recover and adapt. Rosati et al. (2015) expand on the four resilience concepts and summarize the methods of quantifying coastal system resilience.

The "prepare" concept can contain both natural processes and anthropogenic activities to prepare the system for the next disturbance. Preparations often include disaster education in the community, elevating infrastructures, restoring wetlands, beach re-nourishment and building flood protection structures. The "resist" concept refers to the ability to withstand and absorb the disturbance and maintain a certain level of functionality during the disturbance. Coastal structures that mitigate storm damage or evacuating the coastal community at risk are examples of resisting (or avoiding) damage. The "recover" concept is the ability of the system to bounce back to its original state. Recovery can be natural or anthropogenic. For example, beach systems begin to naturally recover immediately following a storm. The volume of sand transported offshore to the sand bar system gradually moves back to the forebeach (Morton et al. 1994). Hence, the availability of sand volume on the dry beach prior to the disturbance plays a key role in beach recovery. Human intervention such as beach nourishment will expedite the recovery process. The "adapt" concept is the adjustment to an improved system state to better withstand or recover from the next disturbance. Adaptation might include the modified design of a nature-based feature.

There are many elements to coastal system resilience such as the economic, social, or political aspects of the community, built urban infrastructure (roads, buildings, erosion control structures) and the natural or engineered physical coastal environment (beach and dune, reef, marsh, etc.). In this study, we examine a resilience index for the beach and dune system, which is usually the first line of resistance for a coastal community. We consider part of the coastal system and recognize that although functionality of the beach and dune system may be lost entirely during a disturbance, that does not necessarily indicate the coastal system lost all functionality or was not resilient.

USGS developed the Coastal Vulnerability Index (CVI), which is an empirical linearization based on 6 regional-scale parameters (Thieler and Hammar-Klose 1999). It can be calculated for past or present conditions. CVI considers geomorphology, coastal slope, relative sea level change rate, shoreline change rate, mean tide range and mean wave height. CVI is calculated as the square root of the geometric mean of these six variables. CVI focuses on long-term coastal vulnerability from physical changes due to sea level rise. The concept is similar to USACE Sustainability concepts that focus on the long-term health of a coastal system.

However, there is not an index that considers short-term response of beach and dune system to seasonal storms, or storm damage reduction benefits in the context of resilience. There is a need for a metric that focuses on project response to unpredicted disturbances and the cumulative CSRM performance over the life of a project. We propose the Coastal Resilience Index (CRI).

\footnotetext{
${ }^{1}$ APTIM, 2481 NW $2{ }^{\text {nd }}$ Avenue, Boca Raton, Florida, 33431, USA

${ }^{2}$ American Shore and Beach Preservation Association, USA

${ }^{3}$ U.S. Army Engineer Research \& Development Center, Coastal \& Hydraulics Laboratory, USA
} 


\section{COASTAL RESILIENCE INDEX}

The Coastal Resilience Index (CRI) considers the beach and dune system (infrastructure) and disturbance factors such as storm surge and waves. The quantification of each concept is discussed below.

\section{Beach and Dune}

Given that coastal system resilience depends on many factors, we begin with one of those elements, the beach and dune system. Following Hurricane Sandy, American Shore and Beach Preservation Association (ASBPA) adopted the simple concept that wide beaches, high dunes and elevated structures help reduce storm damage. These factors were observed in communities that resisted storm damages better than neighboring communities without wide beaches, high dunes, and elevated structures (USACE 2013; Walling et al. 2014).

In this study, an automated tool was developed that extracts morphologic features from beach and dune systems to provide the morphologic metrics for the CRI such as landward limit of dune, dune crest, dune toe, shoreline, and mean beach slope (Figure 1).

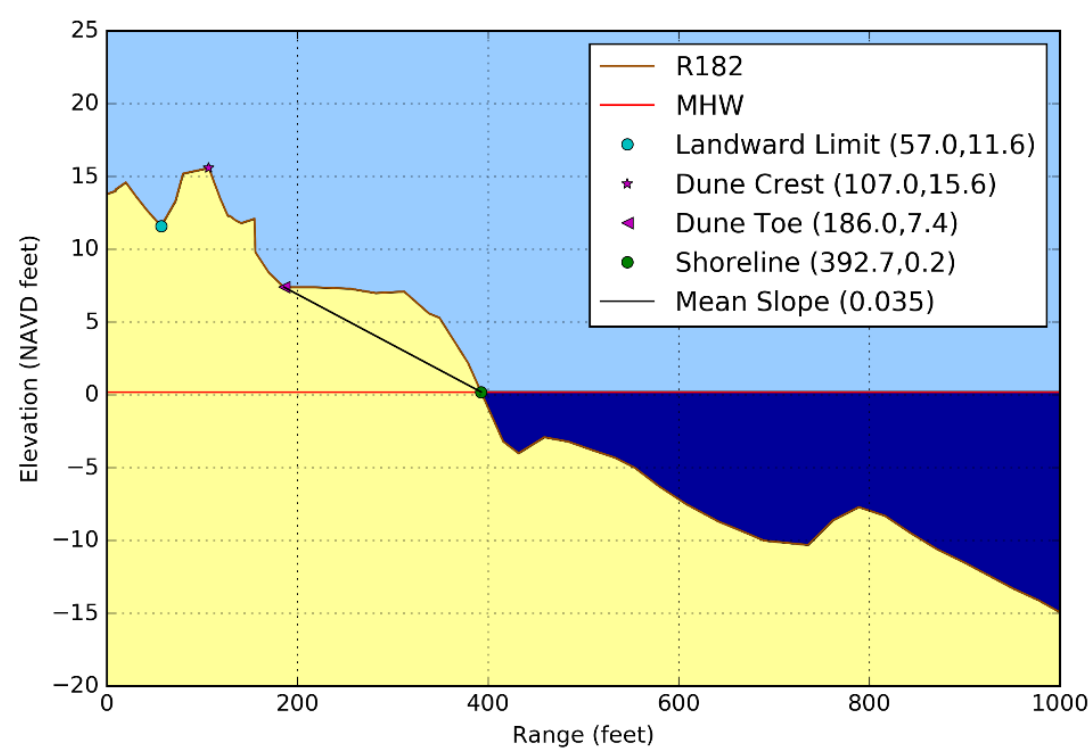

Figure 1. 2004 Delray Beach survey at monument R182, illustrating CRI metrics.

Parameters that are calculated from these morphologic features include protective width (PW), protective elevation (PE), beach volume density (VD) and dune elevation (DE) as shown in Figure 2.

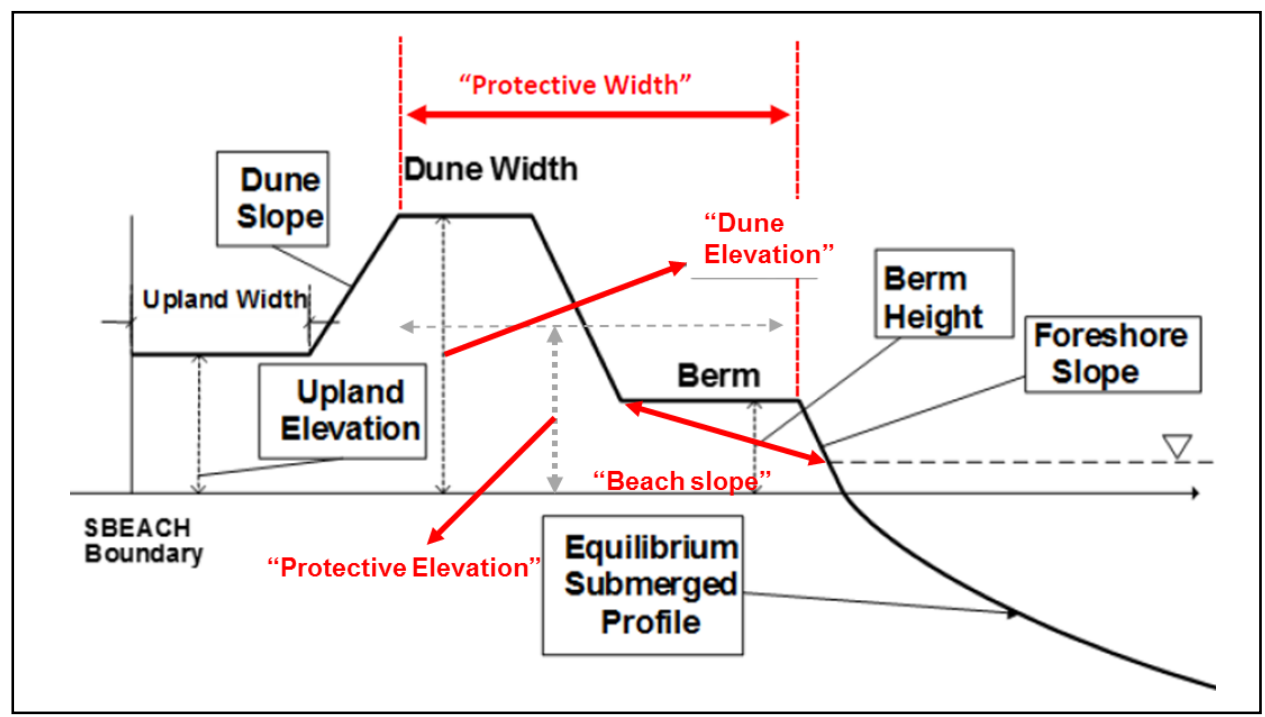

Figure 2. Beach parameters of a typical USACE Beach-fx profile (Rogers et al. 2009) 
The protective width (PW) is defined as the horizontal distance including dune width, seaward dune slope and berm width. The protective elevation (PE) is the average elevation over the protective width portion of the profile. In this study, we calculate the protective elevation above Mean High Water (MHW). The protective elevation represents the average height of the subaerial beach profile. The concepts of protective width and protective elevation correspond to the ASBPA's qualitative statement that wide beaches and high dunes help reduce storm damage. The beach volume density (VD=PW*PE) is related to protective width (PW) and protective elevation (PE). Higher beach volume density indicates wider beaches and higher dunes, which increase the coastal resilience. During a storm, the volume of sand within the protective width can be moved offshore to the sand bar system. This amount of sand will gradually recover to the forebeach after the storm. Therefore, natural beach recovery is related to the volume density within the protective width. Meanwhile, the percentage of fine sediment in the beach system also affects the resilience. The eroded fine sediment can remain in suspension and be transported outside of the beach system (Rosati 2009). In addition to the protective elevation, the dune crest elevation (DE) is also important as it resists wave overtopping. The beach profile parameters (PW, PE, VD, DE) inform the prepare, resist, recover and adapt concepts of the resilience cycle.

\section{Storm Surge and Erosion}

To account for the storm surge contribution to the CRI, we consider maximum storm-induced shoreline recession (MR) and maximum storm surge (MS). The two parameters (MR, MS) provide information as to how USACE CSRM projects resist disturbances. The maximum storm surge may occur during high, low, or mean tide. Therefore, the tide level (TL) is also an important factor. Mean High Water (MHW) is used as the tide level for this study. Based on the comparison between dune elevation and protective width (DE, PW) and storm water level and shoreline recession (MS+TL, MR), the storm event is categorized in three scenarios (Sallenger 2000):

- $\quad(\mathrm{MS}+\mathrm{TL})>\mathrm{DE}$ or $\mathrm{PW}<\mathrm{MR}$

Dune is fully submerged or eroded by the storm, implying minimum resilience, referred to as "Inundation Regime."

- $\quad(\mathrm{MS}+\mathrm{TL})<<\mathrm{DE}$ or PW $>>\mathrm{MR}$

Dune is much higher than the storm water level or much wider than the maximum erosion, implying maximum resilience, referred to as "Swash Regime."

- $\quad(\mathrm{MS}+\mathrm{TL})<\mathrm{DE}$

Dune is slightly higher than the storm water level. The area behind the dune is vulnerable to waveinduced overwash, referred to as "Collision Regime" and "Overwash Regime."

For purposes of this pilot CRI, MS and MR were held constant. The MS and MR variables will be obtained from Project Impact Reports for CSRM projects.

When major disturbances compromise USACE CSRM Projects, a policy trigger may be met. Following a disturbance, the local sponsor of USACE infrastructure projects may request rehabilitation assistance in accordance with Public Law 84-99. A few policy decisions typically take place prior to this request from the local sponsor, such as federal and state emergency declarations that allow for public assistance. The USACE District then prepares a Project Information Report (PIR) detailing the event (i.e., duration and type of impacts) and its effects on the infrastructure project (i.e., morphologic response quantified with topographic and hydrographic surveys on a relatively fine-scale). Events that trigger the preparation of a PIR are proposed to represent model disturbances to the infrastructure project. The PIRs are used as a source to represent model disturbances and to provide historical data on the condition of post-storm CSRM projects.

\section{Wave Run-up}

The wave contribution to coastal resilience is parameterized according to wave run-up and overtopping. The total water level elevation consists of tide, surge and wave-induced run-up, and the latter is usually neglected (Stockdon et al. 2012). When the actual water level (surge and tide) is lower than the dune crest, the area behind the dune is still vulnerable to storm wave-induced run-up and overtopping. The overtopping rate is determined by wave run-up height (WR) and crest freeboard (CF), which is defined as the elevation difference between the storm water level (MS+TL) and dune crest elevation (DE) (Owen 1980, 1982; van der Meer and Janssen 1995).

Smaller crest freeboard and higher wave run-up values indicate larger overtopping rates. Thus, the dune crest elevation (DE) and wave run-up (WR) are important parameters in the resilience quantification. We incorporate the empirical wave run-up model developed by Stockdon (2006). 


$$
W R=1.1\left\{0.35 \beta_{f}\left(H_{0} L_{0}\right)^{1 / 2}+\frac{\left[H_{0} L_{0}\left(0.563 \beta_{f}^{2}+0.004\right)\right]^{1 / 2}}{2}\right\}
$$

The model uses the mean beach slope $\left(\beta_{f}\right)$ and deep water $(20 \mathrm{~m})$ wave height $\left(H_{0}\right)$ and wavelength $\left(L_{0}\right)$ to predict the wave run-up height on the beach face. The mean beach slope of the beach profile is measured from the dune toe to the shoreline. For purposes of this pilot CRI, WR was held at a constant value. For future work, deep-water wave height and wavelength will be obtained from the Project Information Reports.

\section{CRI Equation and Resilience Factors}

CRI is the summation of five non-dimensional factors $(\mathbf{a}, \mathbf{b}, \mathbf{c}, \mathbf{d}, \mathbf{e})$ that incorporate beach, dune, storm and wave parameters. The four characteristic scales $\left(P E_{0}, P W_{0}, C F_{0}, W R_{0}\right)$ are used to nondimensionalize the factors and control the contribution of each factor to the CRI. The CRI is calculated by applying the following:

$$
\begin{gathered}
\boldsymbol{a}=\frac{P E}{P E_{0}} ; \boldsymbol{b}=\frac{P E * P W *(1-s)}{P E_{0} * P W_{0}} ; \boldsymbol{c}=\frac{P W-M R}{P W_{0}} ; \\
\boldsymbol{d}=\frac{D E-(M S+M H W)}{C F_{0}} ; \boldsymbol{e}=\frac{W R_{0}}{W R} \\
\boldsymbol{C R I}=\boldsymbol{a}+\boldsymbol{b}+\boldsymbol{c}+\boldsymbol{d}+\boldsymbol{e}
\end{gathered}
$$

Where,

$P E_{0}$ : Characteristic Protective Elevation, always constant $P W_{0}$ : Characteristic Protective Width, always constant

$C F_{0}$ : Characteristic Crest Freeboard, always constant

$W R_{0}$ : Characteristic Wave runup, always constant

PE: Protective Elevation

PW: Protective Width

s: Percentage of fine sediment

DE: Dune Crest Elevation

MR: Maximum Shoreline Recession

MS: Maximum Storm Surge

WR: Wave Run-up

MHW: Mean High Water

a: Protective Elevation Factor, indicating the average height of dune and berm

b: Volume Density Factor, indicating the volume density of dune and berm

c: Protective Width Factor, indicating the actual Protective Width during the storm

d: Crest Freeboard Factor, indicating the vulnerability to storm surge and wave overwash

e: Wave Run-up Factor, indicating the vulnerability to wave overwash

For this study, the four characteristic scales are set as $P E_{0}=15 \mathrm{ft}, P W_{0}=500 \mathrm{ft}, C F_{0}=20 \mathrm{ft}, W R_{0}=2 \mathrm{ft}$. These values were held constant for application to the pilot study site at Delray Beach, FL based on historical analysis of profile data. These values would vary for future study.

\section{PILOT APPLICATION OF CRI}

The five resilience factors and the CRI are determined from historical profile data obtained in Delray Beach, Florida. The historical data provide both spatial and temporal comparison of coastal resilience, as well as a mean CRI value for the project and a single CRI value for each profile. A method to extract the morphologic features and automate the calculation of the beach parameters (protective width; dune crest, shoreline, etc.) was developed. Resilience factors and CRI are calculated using these parameters.

\section{Beach Morphologic Feature Extraction}

Calculating beach parameters such as protective width and mean beach slope from measured beach morphology is challenging and can be subjective. For example, the dune is not flat in the real world. The measurement of dune width requires identifying the landward and seaward limits of the dune. USGS developed a method to extract the dune crest, dune toe, shoreline position and mean beach slope from three-dimensional LiDAR data (Stockdon et al. 2012; Doran et al. 2015). The Joint Airborne Lidar 
Bathymetry Technical Center of Expertise (JALBTCX) has also developed a toolbox to process LiDAR data in terms of transects and shorelines (Robertson et al. 2018). Similarly, we developed a Python-based ArcGIS toolset to extract the beach morphologic features from various data sources such as LiDAR data and field measurements, and calculate resilience parameters and CRI. The toolset examines each beach profile and identifies the location of landward limit of dune, dune crest, dune toe and shoreline. The shoreline is defined as the location of the intersection of the mean high water (MHW) contour line and the beach profile. The mean beach slope is calculated using the dune toe and shoreline. Meanwhile, tool the plots of each beach profile showing the selected four locations and mean beach slope for QA/QC and fine-tuning the extraction tool (Figure 1).

Protective width (PW) is calculated as the distance from the landward limit to the shoreline. Protective elevation (PE) is the average elevation within the portion of protective width. Dune crest elevation (DE) is the highest point within the portion of protective width. The highest point is considered the landward limit when profiles do not have a dune. The dune toe is defined as the seaward end of the dune slope, where the cross-shore slope suddenly decreases or inflects. However, natural beach profiles usually have several small crests and troughs seaward of the dune, which makes finding the dune toe location more difficult. To avoid extracting dune toe on the berm, Stockdon et al. (2012) uses the high water line (HWL) as the elevation criteria. The dune toe is the intersection location of beach profile and high water contour line in this case. In comparison, our toolset allows users to set the elevation range for dune toe to avoid extracting dune toe locations from excessively high or low positions on the beach profile. The user can first run the toolset without setting the elevation range. After reviewing the results, the user can set the criteria and rerun the toolset to improve results.

Mean beach slope is calculated from the position of dune toe to the shoreline (Stockdon et al. 2012), which is used in the wave run-up model. Maximum shoreline retreat (MR), maximum storm surge (MS), deep water wave height and wavelength have been set as constant for this study.

\section{Historical Profile Data Summary}

Historical profile data measured at Delray Beach, FL were used to calculate the resilience factors and index. A total of 32 survey datasets were collected from Delray Beach profile data by the private firm Coastal Planning and Engineering between 1975 and 2016. Some surveys were collected within the same year for both the pre- and post-nourishment construction conditions.

\section{Results}

The mean CRI and resilience factors for each dataset were calculated by averaging over all the profiles (R175 to R192) at Delray Beach (Figure 3). There were 6 major periodic renourishment projects and 2 small storm repair projects between 1973 and 2014 with a total placed volume of 7,863,000 cubic yards (Table 1). In general, the mean CRI increased from 0.75 in May 1973 to 2.25 in August 2016 at Delray Beach due to the periodic nourishment projects. The contribution of each resilience factor to the CRI requires further study and calibration. However, the trend of each resilience factor time series reflects the benefits of the beach nourishment projects to the resilience of the beach system.

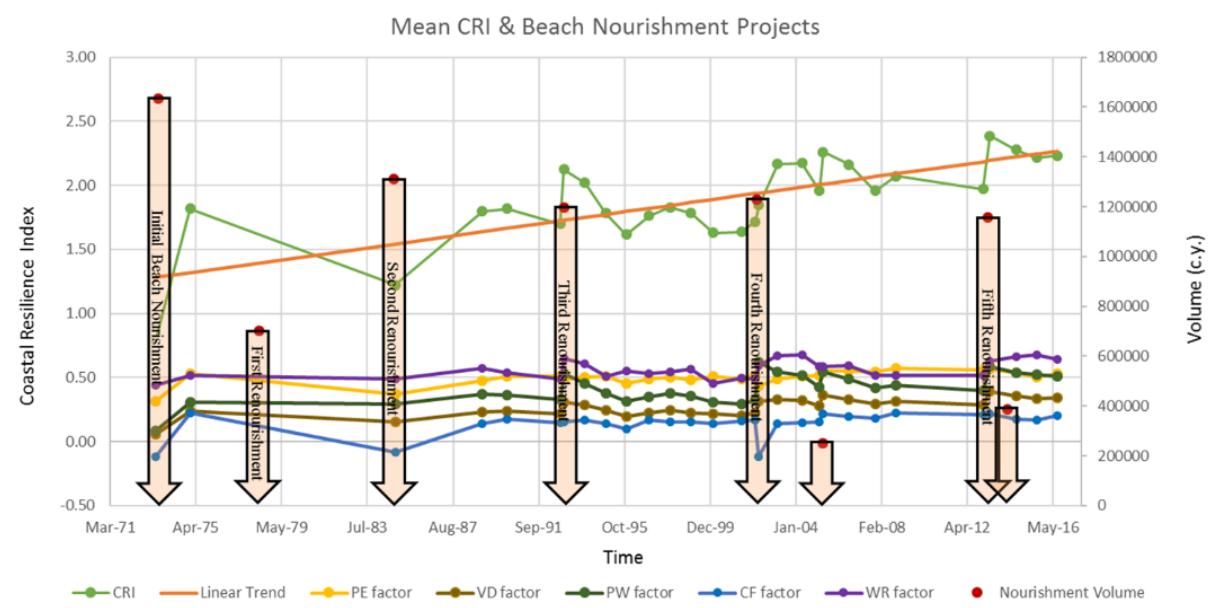

Figure 3. Mean Coastal Resilience Index at Delray Beach, FL 


\begin{tabular}{|c|c|c|}
\hline \multicolumn{3}{|c|}{ Table 1. Delray Beach nourishment events. } \\
\hline Construction Date & Placed Volume (c.y.) & Placed Location \\
\hline 1973 & $1,634,500$ & R-175 to R-188 \\
1978 & 701,300 & R-176 to R-182 and R-186 to R-188 \\
1984 & $1,311,000$ & R-175 to R-188 \\
1992 & $1,196,500$ & R-180 to R-188A \\
2002 & $1,230,000$ & R-179 to R-188A \\
2005 & 250,000 & R-175 to R-188 \\
2013 & $1,158,500$ & R-179 to R-188A \\
2014 & 381,200 & R-175+300 to R-180 \\
\hline
\end{tabular}

Meanwhile, we illustrate how beach nourishment projects affect the resilience index by focusing on the temporal evolution of single profile (Figure 4). Historical profile plots of R182 are shown in Figure 5. The historical profile comparison indicates that the shoreline has been gradually advancing over time. The dune and berm have been widened and elevated. The volume density of the beach profile has significantly increased. Between January 1975 and August 2016, the shoreline advanced about 300 feet at R182. Higher dunes and wider berms suggest higher resilience. In addition, when the berm is widened, the mean beach slope is further flattened, discouraging wave run-up. As a result, the CRI increased from 1.47 in January 1975 to 3.0 in August 2016.

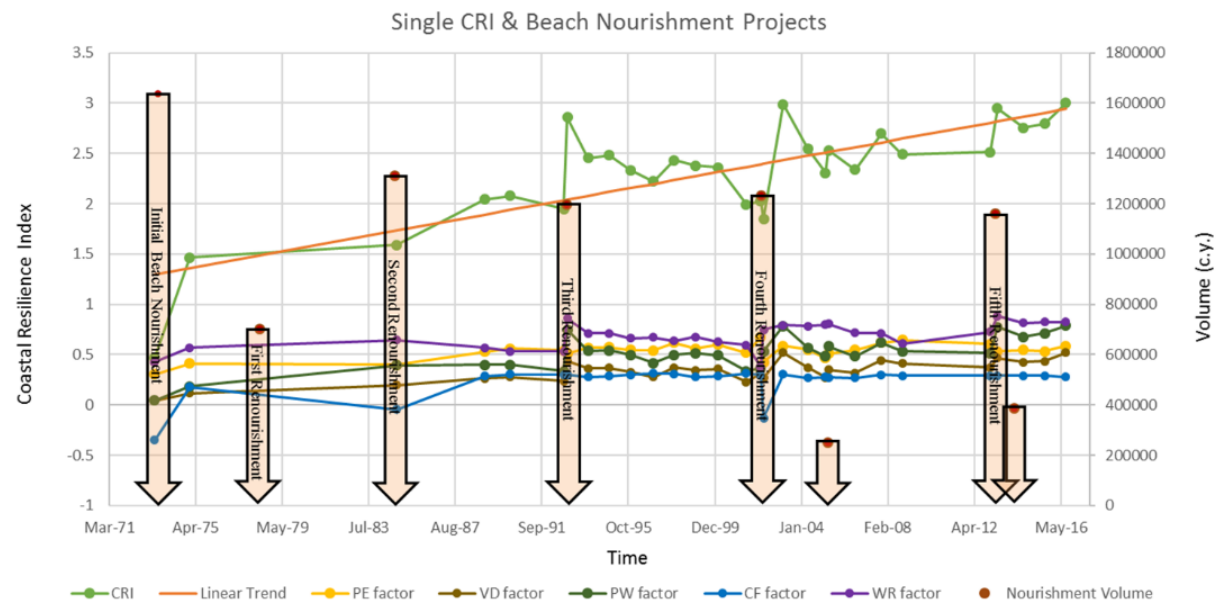

Figure 4. Single Coastal Resilience Index at R182 of Delray Beach, FL

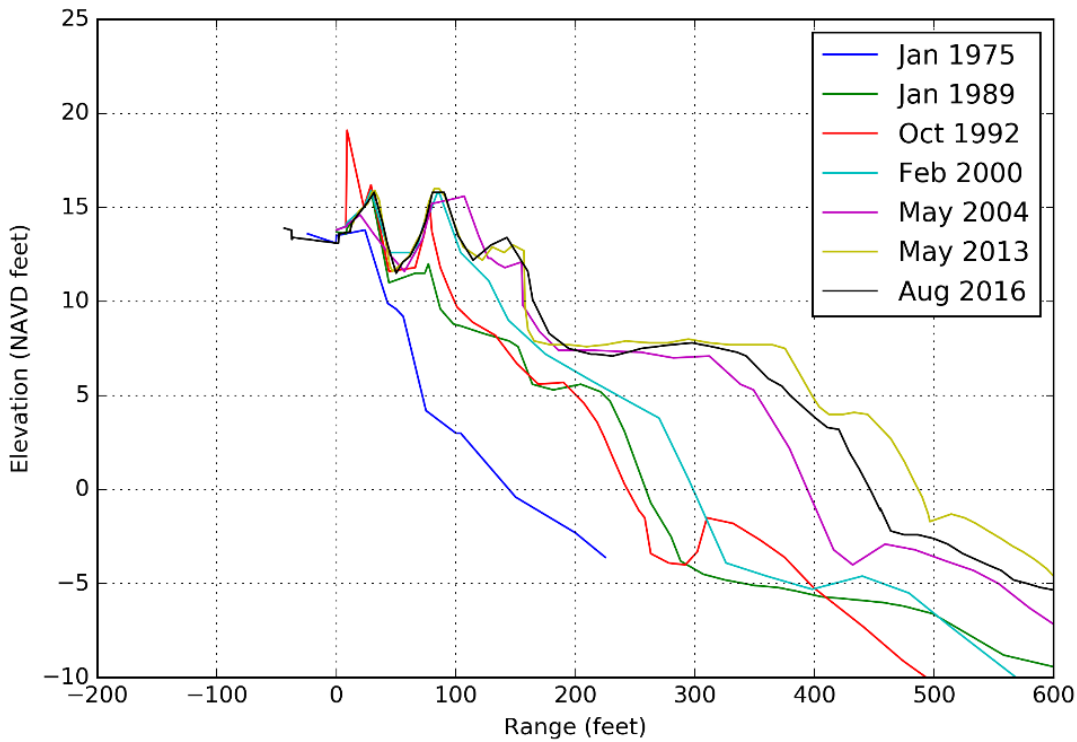

Figure 5. Historical profile surveys at R182 of Delray Beach, FL 
Comparison of mean CRI for May 1973 and August 2016 confirms an increase in resilience over the last several decades (Figure 6). Based on the time series of CRI and historical beach conditions, coastal resilience at Delray Beach is grouped in three categories: Low $(\mathrm{CRI}<1.5)$, Medium $(1.5<\mathrm{CRI}<2)$ and High (CRI >2). Beach and dune system resilience in Delray Beach increased from spatiallyconsistent low values in 1973 to medium to high resilience in 2016.

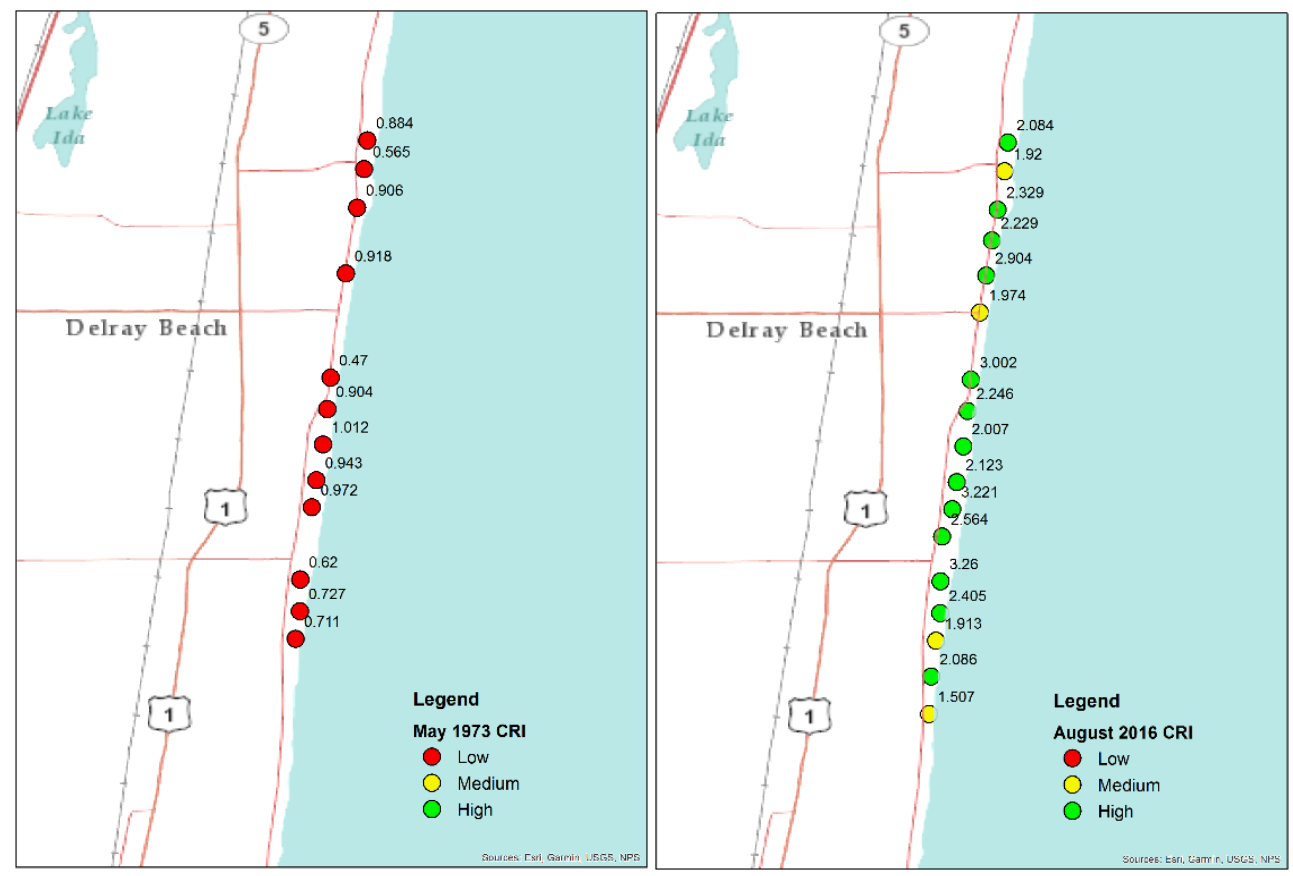

Figure 6. Map view of mean CRI between 1973 and 2016 at Delray Beach, FL

Future work will focus on the calibration of the contribution of each resilience factor, comparison of the CRI from site to site, scaling the storm and wave parameters and creating nationwide CRI maps.

\section{REFERENCES}

Doran, K.S., J.W. Long, and J.R. Overbeck. 2015. A method for determining average beach slope and beach slope variability for U.S. sandy coastlines. U.S. Geological Survey Open-File Report 2015$1053,5 \mathrm{p}$.

Hapke, C.J., O.T. Brenner, and R.E. Henderson. 2015. Quantifying the Geomorphic Resiliency of Barrier Island Beaches. In: Wang, P., J.D. Rosati, and J. Cheng. (eds) Coastal Sediments 2015: Proceedings.

Morton, R.A., J.G. Paine, and J.C. Gibeaut. 1994. Stages and durations of post-storm beach recovery, southeastern Texas coast, USA. Journal of Coastal Research: 884-908.

Owen, M.W. 1980. "Design of Seawalls Allowing for Wave Overtopping," Report No. 924, Hydraulics Research Station, Wallingford, UK.

Owen, M.W. 1982. The Hydraulic Design of Seawall Profiles. Proceedings of the Coastal Protection Conference, Institution of Civil Engineers, Thomas Telford Publishing, London, UK, pp 185-192.

Robertson, Q., L. Dunkin, Z. Dong, J. Wozencraft, K. Zhang. 2018. Florida and US East Coast Beach Change Metrics Derived from LiDAR Data Utilizing ArcGIS Python Based Tools. In: Botero C., Cervantes O., Finkl C. (eds) Beach Management Tools - Concepts, Methodologies and Case Studies. Coastal Research Library, vol 24. Springer, Cham.

Rogers, C.M., A.J. Kristine, and M. Gravens. 2009. Beach-fx User's Manual: Version 1.0 Report No. ERDC/CHL SR-09-6. Army Engineer Research and Development Center, Coastal and Hydraulics Laboratory 3909 Halls Ferry Road, Vicksburg, MS 39180-6199. 262 pages.

Rosati, J.D. 2009. Barrier Island Migration over a Consolidating Substrate. LSU Doctoral Dissertations. Rosati, J.D., K.F. Touzinsky, W.J. Lillycrop. 2015. Quantifying coastal system resilience for the US Army Corps of Engineers. Environ. Systems and Decisions, vol. 35, pp. 196-208.

Sallenger, A.H. Jr. 2000. Storm Impact Scale for Barrier Islands. Journal of Coastal Research, 16(3), 890-895. 
Stockdon, H.F. 2006. Predicting the Longshore-Variable Coastal Response to Hurricanes. OSU Doctoral Dissertations.

Stockdon, H.F., K.J. Doran, D.M. Thompson, K.L. Sopkin, N.G. Plant, and A.H. Sallenger. 2012. National assessment of hurricane-induced coastal erosion hazards: Gulf of Mexico. U.S. Geological Survey Open-File Report 2012-1084, 51 p.

Stockdon, H.F., D.M. Thompson, N.G. Plant, J.W. Long. 2014. Evaluation of wave runup predictions from numerical and parametric models. Coastal Engineering, vol. 92, pp. 1-11.

Thieler, E.R., and E.S. Hammar-Klose. 1999. National Assessment of Coastal Vulnerability to Sea-Level Rise: Preliminary Results for the U.S. Atlantic Coast, U.S. Geological Survey Open-File Report 99593.

USACE, 2013, Hurricane Sandy Coastal Projects Performance Evaluation Study. U.S. Army Corps of Engineers, Assistant Secretary of the Army for Civil Works, Report to Congress, Disaster Relief Appropriations Act.

van der Meer, J.W., and W. Janssen. 1995. Wave Run-Up and Wave Overtopping at Dikes. In Wave Forces on Inclined and Vertical Wall Structures, Kobayashi and Demirbilek, (eds). American Society of Civil Engineers, pp 1-27.

Walling K., J.K. Miller, T. Herrington, A. Eble. 2014. Comparison of Hurricane Sandy impacts in three New Jersey coastal communities. Coastal Engineering Proceedings, [S.1.], n. 34, p. management.38. ISSN 2156-1028. 